\title{
Controlled pilot study of rapid amphotericn B infusions
}

H Dele Davies, Susan M King, John Doyle, Anne Matlow, Gideon Koren, Robert Hamilton, Carol Portwine

\begin{abstract}
This pilot study compared the toxicity of a one hour with a four hour amphotericin $B$ infusion in children. There were more severe chills in the former group on the first day of infusion, and more hypotension in the latter group over the study duration.

(Arch Dis Child 1997;76:165-166)
\end{abstract}

Keywords: amphotericin B; toxicity.

Cumulative evidence in adults suggests that short duration infusions of amphotericin B have similar side effects to longer duration infusions, ${ }^{1-5}$ but there are no studies in children. We report a randomised, placebo controlled, double blinded pilot study of infusion related toxicity of one compared with four hour infusions of amphotericin B in children.

\section{Methods}

The study was conducted at the Hospital for Sick Children, Toronto, Canada from 1 November 1992 to 30 October 1993. Children aged between 1 month and 19 years prescribed amphotericin B treatment were enrolled. Exclusion criteria included: creatinine clearance $<50 \%$ of age normal, as estimated using serum creatinine concentrations, ${ }^{6}$ uncontrolled congestive heart failure or life threatening arrhythmias, amphotericin B infusion within one week of study, and failure to obtain informed consent. The study was approved by the hospital ethics review committee.

Eligible children were randomised by pharmacy in blocks of four into two groups: group 1 , children who received daily one hour infusions and group 2, those who received daily four hour amphotericin B infusions for four days. Demographic and clinical data and a 14 lead electrocardiogram were obtained at baseline as were daily measurements of serum sodium, potassium, chloride, calcium, magnesium, blood urea nitrogen, creatinine, aspartate aminotransferase, alkaline phosphatase, and complete blood counts. A continuous cardiac monitor with alarm was attached and a study nurse/investigator was always at the bedside during infusions.

The initial dose of amphotericin B was 0.5 $\mathrm{mg} / \mathrm{kg}$ body weight, diluted in $10 \mathrm{ml}$ of $5 \%$ dextrose solution per $1 \mathrm{mg}$ of drug and was increased to $1 \mathrm{mg} / \mathrm{kg} /$ day as needed or tolerated. For group 1, all of the amphotericin $\mathrm{B}$ dose was infused in one bag over one hour, followed by a second identical appearing bag containing $5 \%$ dextrose, water, and multivitamins, infused over three hours. For group 2 infusions, $25 \%$ of the amphotericin B dose was infused in one bag over one hour, while the remaining $75 \%$ of the dose was infused in a second bag over three hours. All patients were premedicated with $1 \mathrm{mg} / \mathrm{kg}$ of diphenhydramine and $10 \mathrm{mg} / \mathrm{kg}$ of acetaminophen. Meperidine hydrochloride $(0.6 \mathrm{mg} / \mathrm{kg})$ was given for chills lasting more than five minutes and hydrocortisone $(1 \mathrm{mg} / \mathrm{kg})$ was infused for chills lasting more than 10 minutes. Chills were graded between 0 and 3 using a previously described ordinal chill scale. ${ }^{5}$ A tympanic thermometer was used for measurement of temperature. Hypotension was defined as a decrease in systolic or diastolic blood pressure of more than $20 \%$ from the baseline, or a fall to less than 2 SDs for age normal.

Group proportions were compared using $\chi^{2}$ or Fisher's exact test, with $\mathrm{p}<0.05$ considered statistically significant. Repeated measures analysis of variance (ANOVA), with temperature and pulse as repeated measures, was used to compare groups over each of the four different infusion times.

\section{Results}

Twelve patients were randomised into each group (table 1). Six patients in group 1 and 11 in group 2 completed all four days of infusion. The mean chill scores of those who developed chills are shown in fig 1 . In group 1, three patients with chill scores of 3 were withdrawn after day 1 by their parents and three others had their treatment stopped after day three because the attending physician felt it was no longer clinically indicated. One patient in group 2 was withdrawn after day 2 because of symptomatic bradycardia.

Mean (SD) temperature during infusions was $37.7(1.5)^{\circ} \mathrm{C}$ for group 1 compared with $37.3(1.0)^{\circ} \mathrm{C}$ for group 2 patients. There was no difference in the changes in temperature from baseline between the two groups $(p=0.80$, repeated measures repeated measures ANOVA). Four patients in group $1(33.3 \%)$ and two patients in group $2(16.7 \%)$ developed hypothermia (temperature $<35.9^{\circ} \mathrm{C}$ ).

There was no difference in the mean pulse rate between groups over the infusion period $(p=0.14$, repeated measures ANOVA). Two group 1 and no group 2 patients developed systolic hypotension, while three patients in group 1 and seven in group 2 developed diastolic hypotension. 
Table 1 Characteristics of patients in the two infusion groups before amphotericin $B$ infusions

\begin{tabular}{|c|c|c|}
\hline \multirow[b]{2}{*}{ Characteristic } & \multicolumn{2}{|c|}{ Duration of infusion } \\
\hline & $\begin{array}{l}\text { One hour } \\
\text { (group 1, } n=12 \text { ) }\end{array}$ & $\begin{array}{l}\text { Four hours } \\
\text { (group } 2, n=12 \text { ) }\end{array}$ \\
\hline Males/females ${ }^{\star}$ & $10 / 2$ & $5 / 7$ \\
\hline Age range (years) & $0.4-16.1$ & $0.1-18.4$ \\
\hline Mean (SD) age (years) & $5.7(5.4)$ & $6.6(6.5)$ \\
\hline No with neutropenia & 9 & 8 \\
\hline No with fever & 11 & 9 \\
\hline No with confirmed fungal infections & 2 & 4 \\
\hline \multicolumn{3}{|l|}{ Underlying diagnosis } \\
\hline Acute lymphocytic leukaemia & 2 & 4 \\
\hline Acute monocytic leukaemia & 3 & 4 \\
\hline Non-Hodgkin's lymphoma & 0 & 1 \\
\hline Rhabdomyosarcoma & 1 & 0 \\
\hline Neuroblastoma & 1 & 0 \\
\hline Wilms' tumour & 0 & 1 \\
\hline Severe combined immunodeficiency & 0 & 1 \\
\hline Immunodeficiency & 1 & 0 \\
\hline Bone marrow transplant & 1 & 0 \\
\hline Aplastic anaemia & 1 & 0 \\
\hline Short gut syndrome & 0 & 1 \\
\hline Chronic candidal mastoiditis & 1 & 0 \\
\hline Histiocytosis X & 1 & 0 \\
\hline
\end{tabular}

${ }^{\star} \mathrm{p}$ Value $=0.04$

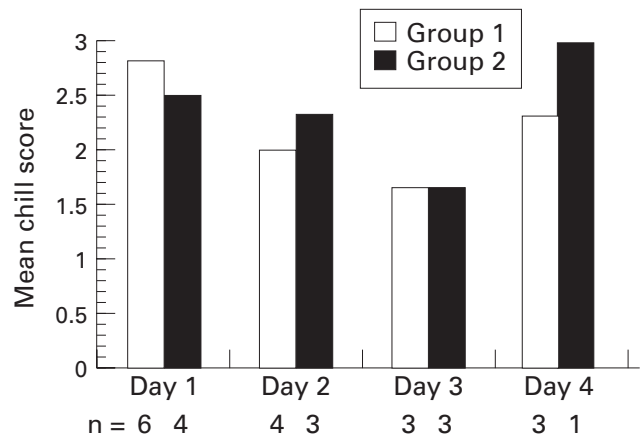

Figure 1 Mean chill score for each group for those with chills by day of infusion.

Hypokalaemia occurred in no group 1 and one group 2 patient. Two patients in each group had creatinine clearance rates that dropped to $<50 \%$ of normal. No patients in either group had abnormalities in liver function, calcium, or magnesium during or up to one week after the study. No patients died during or within one week after their infusion was discontinued.

\section{Discussion}

In the present pilot study, we found similar toxicity associated with one and four hour amphotericin B infusions in children. However, the withdrawal of three children in the rapid infusion group on day 1 suggests greater severity of chills. For patients who remained in the study, the similarities in mean chill score in the two groups after day 1 suggests that one approach to minimising the chill effect is to give the first dose as a standard (four hour) infusion, with subsequent infusions given over one hour.

Although no patients had arrhythmias, the most serious infusion related toxicity of amphotericin $\mathrm{B}$, it is notable that the only patient to develop symptomatic bradycardia was in the standard infusion arm, and more patients with diastolic hypotension were also in this group. Since one hour infusions for children have the potential benefit of ease in scheduling other medications, total parental nutrition, and outpatient treatment, a larger trial is warranted.

The authors gratefully acknowledge the editorial assistance of Helen Kominic, nurses Helena Makkonen and Jennifer Craven, and the statistical assistance of Derek Stevens.

The study was supported by a grant from the Physician Services Incorporated Foundation of Ontario. H Dele Davies was supported by the Eli Lilly Canadian Infectious Diseases Fellowship Award and the Ontario Ministry of Health Research Personnel Development Award.

This work was presented in part at the 34th InterScience Conference on Antimicrobial Agents and Chemotherapy, Orlando, Florida, October 1994.

1 Oldfield EC III, Garst PD, Hostettler C, White M, Samuelson D. Randomized, double-blind trials of 1-versus 4-hour amphotericin B infusion durations. Antimicrob Agents Chemother 1990;34:1402-6.

2 Spitzer TR, Creger RJ, Fox RM, Lazarus HM. Rapid infusion of amphotericin B: effective and well-tolerated therapy sion of amphotericin B: effective and well-tolerated therap

3 for neutropenic fever. Pharmatherapeutica 1989;5:305-11. Cruz JM, Peacock JE Jr, Loomer L, et al. Rapid intravenous
infusion of amphotericin B: a pilot study. Am $\mathcal{J}$ Med 1992; 93:123-30.

4 Arning M, Dresen B, Aul C, Schneider W. Influence of infusion time on the acute toxicity of amphotericin B: results of a randomized, double-blind study. Recent Results Cancer Res 1991;121:347-52

5 Ellis ME, al-Hokail AA, Clink HM, et al. Double-blind randomized study of the effect of infusion rates on toxicity of amphotericin B. Antimicrob Agents Chemother 1992;36:1729.

6 Schwartz G, Brion L, Spitzer A. The use of plasma creatinine concentration for estimating glomerular filtration rate in infants, children, and adolescents. Pediatr Clin North Am 1987;34:571-90. 